Article

\title{
Vitamin C Supplementation and Hyperuricemia: Fact or Hoax?
}

\author{
Firas S. Azzeh ${ }^{1, *}$, Abrar H. Al-Hebshi ${ }^{1}$, Haya D. Al-Essimii ${ }^{1}$, Mohammed A. Alarjah ${ }^{2}$ \\ ${ }^{1}$ Department of Clinical Nutrition, Faculty of Applied Medical Sciences, Umm Al-Qura \\ University, P.O. Box: 7067, Makkah (21955), Saudi Arabia \\ ${ }^{2}$ Faculty of Pharmacy, Umm Al-Qura University, P.O. Box: 7067, Makkah (21955), Saudi \\ Arabia
}

*Correspondence: fsazzeh@uqu.edu.sa; Telephone: +966-540833661;

Fax: +966-25720000-4227

\begin{abstract}
Hyperuricemia is commonly diagnosed in subjects with abnormal purine metabolism. Prolonged hyperuricemia often associated with gout, which is a vital risk factor for joint dysfunction. The current study was designed to determine the efficacy of vitamin $\mathrm{C}$ supplements for treatment of high serum uric acid (UA) among hyperuricemic and gouty patients, and finding-out the effect of supplementation on serum creatinine $(\mathrm{Cr})$ level and glomerular filtration rate (GFR). This intervention study was started in April, 2013, till two months. A convenient sample of 30 adults aged between 24-75 years of both genders was assigned into two study groups: hyperuricemic $(n=15)$ and gouty $(n=15)$ groups. Each participant supplemented with $500 \mathrm{mg}$ /day vitamin $\mathrm{C}$ chewable tablets for 2 months. Serum $\mathrm{UA}, \mathrm{Cr}$, and GFR were measured before and after treatment. At the end of this study, $\mathrm{Cr}$ and GFR enhanced insignificantly in both groups. UA increased insignificantly in gouty group after 2 months by about $0.31 \mathrm{mg} / \mathrm{dl}$. On the other hand, hyperuricemic group showed significant $(\mathrm{P} \leq 0.05)$ decrease in UA $(-0.78 \mathrm{mg} / \mathrm{dl})$ after 2 months duration. In conclusion, supplementation with $500 \mathrm{mg} /$ day vitamin $\mathrm{C}$ for 2 months significantly attenuated serum UA for hyperuricemic patients and insignificantly affected serum UA in gouty patients. The uselessness of vitamin $\mathrm{C}$ supplements on gouty patients could be associated to a number of possible reasons.
\end{abstract}

Keywords: vitamin C; hyperuricemia; gout; glomerular filtration rate

\section{Introduction}

Hyperuricemia is the precursor of gout disease and it is characterised by a chronic elevation of serum uric acid (UA) [1]. A recent systematic review of population-based epidemiological studies showed a high prevalence of hyperuricemia throughout all regions of the world [2], and Saudi Arabia alone has a hyperuricemia prevalence of 8\% [3]. In a 5year follow-up, $18.8 \%$ of the patients with hyperuricemia developed gout [4]. This disease is consisting of deposits of UA forming monosodium urate crystal in peripheral joints causing episodes of acute pain [2]. The global burden of this inflammatory arthritis disease (gout) has increased in many parts of the world over the past decade [5]. 
Vitamin $\mathrm{C}$ is considered one of the protective modifiable factors against hyperuricemia by its uricosuric effect. Recently, findings of a prospective cohort study suggested that vitamin $\mathrm{C}$ supplementation has a reduction effect on serum UA concentrations that might be beneficial in the prevention of gout [6]. The results of a meta-analysis of 13 randomized controlled trials support the potential evidence for the inverse association between increased vitamin $\mathrm{C}$ intake and the risk of hyperuricemia [7]. Where both vitamin C and UA have similar antioxidant properties, it has been reported that supplementation with the former reduces the serum level of the latter [8]. Moreover, vitamin $\mathrm{C}$ has the ability to recompense for the attenuated antioxidant capacity arising from the decrease in UA level [8]. These dual functions may have important implications for the management of gout. Underlying mechanisms have been proposed to the uricosuric effect of vitamin $\mathrm{C}$ are explained by either increase the glomerular filtration rate (GFR) or competition for renal reabsorption of UA [9].

The purpose of this study is to determine the efficacy of vitamin $\mathrm{C}$ supplements for treatment of high serum UA among hyperuricemic and gouty patients, and finding-out the effect of supplementation on serum creatinine ( $\mathrm{Cr}$ ) level and GFR. To our knowledge, this is the first intervention study that combined between hyperuricemia and gouty patients among Saudi population.

\section{Materials and Methods}

\subsection{Subjects}

A convenience sample of 30 adults from both genders aged between 24-75 years old with hyperuricemia (serum UA $>6 \mathrm{mg} / \mathrm{dl}$ for females and $>7 \mathrm{mg} / \mathrm{dl}$ for males) or diagnosed with gout before at least one year were recruited from Doctor Abdulrahman Taha Bakhsh Hospital in Jeddah (Saudi Arabia). Exclusion criteria were; patients less than 20 years, history of dialysis, alcohol consumption, pregnant or lactating women, muti-vitamins supplements during the last three months, and diuretic drug usage. All patients stopped consuming Allopurinol drug (uricostatic agent) once they started the study. This study was permitted by the Ethical Committee of Umm Al-Qura University, Makkah, Saudi Arabia, following the rules of the Declaration of Helsinki. All eligible subjects completed the consent form before they participated in the study.

\subsection{Study Protocol}

This experimental trial started in April, 2013, and ended in June, 2013. Eligible persons were assigned into two study groups: hyperuricemic (HUG; $n=15)$ and gouty (GG; $\mathrm{n}=15$ ) groups. Nine and seven males were recruited in GG and HUG, respectively. Groups were matched for their age, gender, serum UA, and Cr level. At the beginning of this work, a basic information questionnaire was filled by each participant, including: personal information, educational level, medical and drug history information, family history with hyperuricemia, and anthropometric measurements. Nutritional counseling about their disease, the relation between vitamin $\mathrm{C}$ and the disease, avoidance of high purine foods, medical conditions that could affect health status and other nutritional recommendations were 
all explained to the patients. Each participant supplemented with $500 \mathrm{mg} /$ day vitamin $\mathrm{C}$ chewable tablets (Tabuk Pharmaceutical Manufacturing Company, Tabuk, KSA), which were purchased from local pharmacies. All applicants have been followed-up for 8 weeks. Therefore, blood samples were collected two times from each participant; at the beginning and at the end of study period.

\subsection{Biochemical Analyses}

Blood samples were withdrawn after twelve hours fasting, then they were centrifuged at $4500 \mathrm{rpm}$ for 6 minutes at room temperature by normal centrifuge. Serum specimens were portioned and stored at $-30{ }^{\circ} \mathrm{C}$ for biochemical tests. Serum UA and $\mathrm{Cr}$ concentrations were analyzed using Dimension Vista System instrument (SIEMEMS, Camberley, UK) available in the hospital. Estimated GFR in $\mathrm{ml} / \mathrm{min} / 1.73 \mathrm{~m}^{2}$ was calculated according to the Modification of Diet in Renal Disease equation by Levey et al. [10] as: GFR $=186 \times$ (serum creatinine in $\mathrm{mg} / \mathrm{dl})^{-1.154} \times$ age $^{-0.203} \times 0.742$ (if female) $\times 1.21$ (if African origin).

\subsection{Statistical Analysis}

Statistical analysis was performed using SPSS software (Statistic Package for Social Sciences) version 20. T-student and chi-square tests were performed to find the significant difference between continuous and categorical data, respectively. Data were presented in tables as mean and standard deviation or as frequency and percent. $p$-value $<0.05$ was considered statistically significant.

\section{Results}

All recruited subjects completed the study treatment. The baseline characteristics of participants are shown in Table 1. The mean age for GG was about 50 years and for HUG was 54 years. The mean BMI for GG and HUG were around $31 \mathrm{~kg} / \mathrm{m}^{2}$ and $33 \mathrm{~kg} / \mathrm{m}^{2}$, respectively. Average serum UA in $\mathrm{mg} / \mathrm{dl}$ for GG was 8.09 and for HUG was 7.94. The mean serum $\mathrm{Cr}$ for $\mathrm{GG}$ was $1.08 \mathrm{mg} / \mathrm{dl}$ and for $\mathrm{HUG}$ was $1.06 \mathrm{mg} / \mathrm{dl}$. Estimated GFR $\left(\mathrm{ml} / \mathrm{min} / 1.73 \mathrm{~m}^{2}\right)$ for $\mathrm{GG}$ and $\mathrm{HUG}$ were 79.51 and 75.15 , respectively. No significant differences were observed in the previous parameters between the two groups. In addition, family history with hyperuricemia was noticed in $26.7 \%(n=4)$ in GG and $13.3 \%(n=2)$ in HUG. Only 3 participants in the GG and 2 in HUG were smokers. The duration of hyperuricemia was significantly $(p<0.05)$ higher in GG $(40 \%$ : $>5$ years $)$ than HUG $(73.3 \%$ : $<3$ years), with average values of 4.67 years \pm 2.16 and 2.73 years \pm 1.33 , respectively. No significant difference was perceived in history of kidney stones and the chronic diseases between the groups (diabetes, hypertension, hypertriglyceridemia, cardiovascular diseases, and thyroid disorders; Table 1).

Table 2 demonstrates UA, Cr, and GFR values for the study groups during 2 months study period. The mean serum UA at zero time for GG $(8.09 \mathrm{mg} / \mathrm{dl})$ was not significantly different than HUG (7.94 mg/dl). After two months, serum UA for GG increased $(p>0.05)$ and for HUG decreased $(p<0.05)$. Figure 1 illustrates this change in UA after 8 weeks of 
supplementation. Average $\mathrm{Cr}$ level insignificantly decreased for both groups after 8 weeks, which consequently resulted in an insignificant increase in GFR.

Table 3 shows the average changes in UA for GG and HUG during the study period. For GG, UA increased insignificantly after 2 months by about $+0.3 \pm 0.14 \mathrm{mg} / \mathrm{dl}$. On the other hand, HUG showed a significant $(p<0.05)$ decrease in UA after 2 months of study period by about $-0.78 \mathrm{mg} / \mathrm{dl}$. The reduction of UA was slightly higher for women than men.

\section{Discussion}

Dietary approaches have long been identified as important factors in management and prevention of hyperuricemia and related diseases. In this study, supplementation with vitamin $\mathrm{C}$ at $500 \mathrm{mg} /$ day for 8 weeks significantly decreases serum UA in hyperuricemic patients ($0.78 \mathrm{mg} / \mathrm{dl}$ ) compared to an insignificant increase of serum UA in patients with gout disease $(+0.3 \mathrm{mg} / \mathrm{dl})$. These findings are in accordance with Huang et al. [9] who reported an inverse correlation of serum UA with serum ascorbic acid in hyperuricemic individuals after 2 months supplementation of vitamin C $(500 \mathrm{mg} /$ day $)(p<0.0001)$ compared to placebo group (mean changes $-0.5 \mathrm{mg} / \mathrm{dl}$ and $+0.09 \mathrm{mg} / \mathrm{dl}$, respectively). Moreover, our findings strongly agree with Stamp et al. [11] who found no significant difference in serum UA levels between gout patients group who did or did not take vitamin $C$ supplementation ( $500 \mathrm{mg} /$ day) after 8 weeks, despite the increase in plasma ascorbate levels. Likewise, many other meta-analysis of randomized controlled trails and cross sectional studies have reported the urate lowering effects of modest oral dosage of vitamin C supplements in hyperuricemic subjects, as well as the promising role of this viamin in risk reduction of gout [1,6,7,12]. Although, these previuos papers have evaluated the efficacy of oral vitamin $\mathrm{C}$ supplementaion on UA level, Biniaz et al. [13] found that post-heamodialysis intravenous injection of vitamin $\mathrm{C}$ in hyperuricemic chronic kidney disease patients significantly reduces serum UA levels $(p<$ 0.001 ) in comparison to control groups ( $p=0.09$ and $p=0.39$ ).

The dose of $500 \mathrm{mg}$ /day of vitamin $\mathrm{C}$ supplements used in this study was based on that used in earlier studies. Although the dosage of $500 \mathrm{mg} /$ day of vitamin $\mathrm{C}$ is greater than the recommended daily allowance $(75 \mathrm{mg} /$ day in females and $90 \mathrm{mg} /$ day in males), several clinical trials noted that vitamin $\mathrm{C}$ intake is well tolerated in the general population and safe at $\leq 2000 \mathrm{mg}$ /day for adults (tolerable upper intake level), as well as no clinically significant safety issues or any other critical side effects have appeared at any intake [14].

The mechanisms for the urate lowering effect by vitamin $\mathrm{C}$ have been proposed in previous studies. It has been suggested that vitamin $\mathrm{C}$ has a biological uricosuric effect that modulates serum concentration of UA, as both reabsorbed via an anion-exchange transport system at proximal tubule $[1,6,7,12]$. Therefore, high concentration of vitamin $\mathrm{C}$ may competitively impede renal reabsorption of UA in the apical brush border of the proximal tubule through cis-inhibtion of either sodium-dependent anion cotransporter (SLC5A8/A12), UA transport molecules (such as URAT1, the main target of uricosurics) or both (ibid). Furthermore, other potential uricosuric action of vitamin $\mathrm{C}$ might be as a result of its antioxidant property. The antioxidant action of vitamin $\mathrm{C}$ probably enhances GFR by reducing microvascular ischemia in glomeruli, dilation of afferent arteriole and subsequent 
increase in blood flow at the site [9]. Besides, as a consequence of vitamin $\mathrm{C}$ antioxidant action, it may possibly reduce inflammation and body cells damage by free radical, and therefore, attenuate synthesis and production of UA [1,7].

In our study, although high intake of vitamin $C$ reduced serum UA concentration in hyperuricemic group, gouty patients in the other group showed an insignificant increase in UA despite high supplement dosage for 2 months. There are several possible reasons why vitamin $\mathrm{C}$ supplementation in this group of patients had no clinically significant uratelowering outcomes. It appears that the dosage of $500 \mathrm{mg} /$ day vitamin $\mathrm{C}$ is inadequate in gouty patients when administered as monotherapy in comparison to the earlier findings of subjects with hyperuricemia. It is well known that hyperuricemia in most patients with gout is due to kidney underexcretion of uarte, thus, the uricosuric effect of vitamin $\mathrm{C}$ may be insufficient to alter UA transport at proximal tubule in these patients and subsequently incapable of decreasing UA levels when compared to healthy subjects with normal urinary urate excretion. Therefore, supplementation with vitamin $\mathrm{C}$ at $500 \mathrm{mg}$ /day in our gouty study sample might be, to some extent, impotent. In another study, when ascorbic acid was administered intravenously for a short-term at larger doses (infusion rates start with 0.25-1 gm, then increased and varied from 2.5 to $10 \mathrm{gm} /$ minute) in patients with and without gout, significant increase in UA excretion was observed in both study groups with no difference between them [15]. Despite the fact that larger doses of the vitamin may result in higher reduction of UA concentration, long-term impact of such mega dosage is not without critical adverse outcomes [11].

Besides vitamin $\mathrm{C}$ dosage and renal impairment, vitamin $\mathrm{C}$ action may be diminished in the presence of other medications such as diuretics or aspirin [11]. Despite the exclusion of diuretic-use patients in our study sample, some patients had other comorbidities such as hypertension and vascular diseases that may result in using aspirin, and the risk of stopping such medicine outweighs its potential benefits. Previous papers have investigated the mixed effect of aspirin on UA excretion, and reported that high aspirin dose ( $>3 \mathrm{gm} /$ day) has a uricosuric action, while low aspirin intake between 1 and 2 gm/day (or $<325 \mathrm{gm} /$ day) interferes with UA clearance, resulting in its retention and concomitant elevation in serum UA concentration [16,17]. It is hypothesized that aspirin may counteract with UA at reabsorption receptors, reduce its secretion at proximal tubule and probably suppress GFR [7].

There are many other factors that should be monitored in our study sample. First, physical activity level and the intensity of exercise which can affect UA levels in the body. As intense exercise is known to induce oxidative stress and increase salivary and serum UA concentrations [7]. Second, lifestyle factors and patients daily food intake can further influence their UA. Purine-rich foods such as red meats, sweetened beverages and fructose have been identified to increase urate levels, while vitamin C-rich foods, coffee and weight reduction were considered as preventive measures [18]. Moreover, cigarette smoking is negatively correlated with serum ascorbic acid in the body and the risk of sever hypovitaminosis $\mathrm{C}(\leq 0.2 \mathrm{mg} / \mathrm{dl})$ is increased with heavy smoking [19]. Therefore, confounding factors such as the degree of renal impairment, appearance of other medication 
such as aspirin, exercise intensity, food intake history, changes in body weight and smoking should be considered in our study as they have a substantial impact on body urate concentration and effectiveness of vitamin $\mathrm{C}$ action.

\section{Conclusions}

Supplementation with $500 \mathrm{mg}$ /day vitamin C for 2 months significantly attenuated serum UA for hyperuricemic patients and insignificantly affected serum UA in gouty patients. This finding supports the possible role of vitamin $\mathrm{C}$ in the prevention and management of hyperuricemia but not gout disease. Further studies should be undertaken with a larger vitamin dose to investigate it effectiveness on gout disease.

Acknowledgments: The authors thank the staff Doctor Abdulrahman Taha Bakhsh Hospital in Jeddah for their help and support.

Authors' contributions: Firas Azzeh conceived and designed the study. Mohammed Alarjah, Abrar Al-Hebshi and Haya Al-Essimii conducted research, provided research materials, and collected and organized data. Firas Azzeh and Mohammed Alarjah analyzed and interpreted data. All authors wrote initial and final draft of the article. All authors have critically reviewed and approved the final draft of the manuscript.

Conflict of Interest: The authors have declared that no competing interests exist.

\section{References}

1. Gao, X.; Curhan, G.; Forman, J. P.; Ascherio, A.; Choi, H. K. Vitamin C Intake and Serum Uric Acid Concentration in Men. J. Rheumatol. 2008, 35, 1853-1858.

2. Smith, E.; March, L. Global Prevalence of Hyperuricemia: A Systematic Review of Population-Based Epidemiological Studies. ACR Meet. Abstr. 2015.

3. Al-Arfaj, A. S. Hyperuricemia in Saudi Arabia. Rheumatol. Int. 2001, 20, 61-64.

4. Lin, K.; Lin, H.; Chou, P. The interaction between uric acid level and other risk factors on the development of gout among asymptomatic hyperuricemic men in a prospective study. $J$. Rheumatol. 2000, 27, 1501-1505.

5. Kuo, C.-F.; Grainge, M. J.; Zhang, W.; Doherty, M. Global epidemiology of gout: prevalence, incidence and risk factors. Nat. Rev. Rheumatol. 2015, 11, 649-662.

6. Bae, J.; Shin, D. H.; Chun, B.-Y.; Choi, B. Y.; Kim, M. K.; Shin, M.-H.; Lee, Y.-H.; Park, P. S.; Kim, S.-K. The effect of vitamin $\mathrm{C}$ intake on the risk of hyperuricemia and serum uric acid level in Korean Multi-Rural Communities Cohort. Joint Bone Spine 2014, 81, 513-519. 7. Juraschek, S. P.; Miller, E. R.; Gelber, A. C. Effect of oral vitamin C supplementation on serum uric acid: A meta-analysis of randomized controlled trials. Arthritis Care Res. 2011, 63, 1295-1306.

8. Shen, L.; Ji, H. Potential of vitamin C in the prevention and treatment of gout. Nat. Publ. Group 2011, 7, 1. 
9. Huang, H.-Y.; Appel, L. J.; Choi, M. J.; Gelber, A. C.; Charleston, J.; Norkus, E. P.; Miller, E. R. The effects of vitamin $\mathrm{C}$ supplementation on serum concentrations of uric acid: results of a randomized controlled trial. Arthritis Rheum. 2005, 52, 1843-1847.

10. Levey, A. S.; Bosch, J. P.; Lewis, J. B.; Greene, T.; Rogers, N.; Roth, D. A more accurate method to estimate glomerular filtration rate from serum creatinine: a new prediction equation. Modification of Diet in Renal Disease Study Group. Ann. Intern. Med. 1999, 130, 461-470.

11. Stamp, L. K.; O’Donnell, J. L.; Frampton, C.; Drake, J. M.; Zhang, M.; Chapman, P. T. Clinically insignificant effect of supplemental vitamin $\mathrm{C}$ on serum urate in patients with gout: a pilot randomized controlled trial. Arthritis Rheum. 2013, 65, 1636-1642.

12. Choi, H. K.; Gao, X.; Curhan, G. Vitamin C intake and the risk of gout in men: a prospective study. Arch. Intern. Med. 2009, 169, 502-507.

13. Biniaz, V.; Tayebi, A.; Ebadi, A.; Sadeghi Shermeh, M.; Einollahi, B. Effect of vitamin $\mathrm{C}$ supplementation on serum uric acid in patients undergoing hemodialysis: a randomized controlled trial. Iran. J. Kidney Dis. 2014, 8, 401-407.

14. Hathcock, J. N.; Azzi, A.; Blumberg, J.; Bray, T.; Dickinson, A.; Frei, B.; Jialal, I.; Johnston, C. S.; Kelly, F. J.; Kraemer, K.; Packer, L.; Parthasarathy, S.; Sies, H.; Traber, M. G. Vitamins E and C are safe across a broad range of intakes. Am. J. Clin. Nutr. 2005, 81, 736-745.

15. Berger, L.; Gerson, C. D.; Yü, T. F. The effect of ascorbic acid on uric acid excretion with a commentary on the renal handling of ascorbic acid. Am. J. Med. 1977, 62, 71-76.

16. Caspi, D.; Lubart, E.; Graff, E.; Habot, B.; Yaron, M.; Segal, R. The effect of mini-dose aspirin on renal function and uric acid handling in elderly patients. Arthritis Rheum. 2000, $43,103-108$.

17. Louthrenoo, W.; Kasitanon, N.; Wichainun, R.; Sukitawut, W. Effect of minidose aspirin on renal function and renal uric acid handling in healthy young adults. J. Clin. Rheumatol. Pract. Rep. Rheum. Musculoskelet. Dis. 2002, 8, 299-304.

18. Choi, H. K. A prescription for lifestyle change in patients with hyperuricemia and gout. Curr. Opin. Rheumatol. 2010, 22, 165-172.

19. Schectman, G.; Byrd, J. C.; Gruchow, H. W. The influence of smoking on vitamin C status in adults. Am. J. Public Health 1989, 79, 158-162.

Table 1: Baseline and clinical characteristics of participants

\begin{tabular}{lccc}
\hline \multicolumn{1}{c}{ Characteristic } & $\begin{array}{c}\text { Gouty Group } \\
(\mathrm{n}=15)\end{array}$ & $\begin{array}{c}\text { Hyperuricemic } \\
\text { Group }(\mathrm{n}=15)\end{array}$ & $p$-value \\
\hline Age (years) & $49.85 \pm 11.36$ & $54.23 \pm 12.26$ & 0.206 \\
Male, $\mathrm{n}(\%)$ & $9(60 \%)$ & $7(46.7 \%)$ & 0.643 \\
Height $(\mathrm{cm})$ & $170.14 \pm 8.02$ & $162.23 \pm 11.12$ & 0.117 \\
Weight $(\mathrm{kg})$ & $90.42 \pm 19.88$ & $86.92 \pm 21.57$ & 0.726 \\
BMI $\left(\mathrm{kg} / \mathrm{m}^{2}\right)$ & $31.01 \pm 5.01$ & $32.87 \pm 7.33$ & 0.559 \\
\hline
\end{tabular}




\begin{tabular}{|c|c|c|c|}
\hline $\mathrm{UA}(\mathrm{mg} / \mathrm{dl})$ & $8.09 \pm 1.89$ & $7.94 \pm 0.93$ & 0.123 \\
\hline $\mathrm{Cr}(\mathrm{mg} / \mathrm{dl})$ & $1.08 \pm 0.13$ & $1.06 \pm 0.33$ & 0.865 \\
\hline Estimated GFR $\left(\mathrm{ml} / \mathrm{min} / 1.73 \mathrm{~m}^{2}\right)$ & $79.51 \pm 13.1$ & $75.15 \pm 21.18$ & 0.257 \\
\hline Family history with & $4(26.7 \%)$ & $2(13.3 \%)$ & 0.61 \\
\hline \multicolumn{4}{|l|}{ hyperuricemia, n (\%) } \\
\hline Smoking, $\mathrm{n}(\%)$ & $3(20.0 \%)$ & $2(13.3 \%)$ & 0.667 \\
\hline \multicolumn{4}{|l|}{ Duration of hyperuricemia, $\mathrm{n}(\%)$} \\
\hline $1-3$ years & $5(33.3 \%)$ & $11(73.3 \%)$ & 0.001 \\
\hline$>3-5$ years & $4(26.7 \%)$ & $4(26.7 \%)$ & \\
\hline$>5$ years & $6(40 \%)$ & $0(0 \%)$ & \\
\hline \multicolumn{4}{|l|}{ History of kidney stones (\%) } \\
\hline Yes & $4(26.7 \%)$ & $3(20 \%)$ & 0.819 \\
\hline No & $11(73.3 \%)$ & $12(80 \%)$ & \\
\hline \multicolumn{4}{|l|}{ Thyroid disorders $(\%)$} \\
\hline Yes & $2(13.3 \%)$ & $4(26.7 \%)$ & 0.639 \\
\hline No & $13(86.7 \%)$ & $11(73.3 \%)$ & \\
\hline \multicolumn{4}{|l|}{ Cardiovascular diseases $(\%)$} \\
\hline Yes & $2(13.3 \%)$ & $5(33.3 \%)$ & 0.417 \\
\hline No & $13(86.7 \%)$ & $10(66.7 \%)$ & \\
\hline \multicolumn{4}{|l|}{ Hypertension (\%) } \\
\hline Yes & $4(26.7 \%)$ & $6(40 \%)$ & 0.423 \\
\hline No & $11(73.3 \%)$ & $9(60 \%)$ & \\
\hline \multicolumn{4}{|l|}{ Diabetes mellitus (\%) } \\
\hline Yes & $11(73.3 \%)$ & $9(60 \%)$ & 0.423 \\
\hline No & $4(26.7 \%)$ & $6(40 \%)$ & \\
\hline \multicolumn{4}{|l|}{ Hypertriglyceridemia (\%) } \\
\hline Yes & $3(20 \%)$ & $4(26.7 \%)$ & 0.819 \\
\hline No & $12(80 \%)$ & $11(73.3 \%)$ & \\
\hline
\end{tabular}

- $\quad$ Results are considered as Mean $\pm \mathrm{SD}$, or as numbers and percent

- Abbreviations; BMI: Body Mass Index; UA: Uric Acid; Cr: Creatinine; GFR: Glomerular Filtration Rate

Table 2: Uric Acid, creatinine, and estimated GFR for gouty and hyperuricemic groups during the study period

\begin{tabular}{lcc}
\hline & $\begin{array}{c}\text { Gouty Group } \\
(\mathrm{n}=15)\end{array}$ & $\begin{array}{c}\text { Hyperuricemic Group } \\
(\mathrm{n}=15)\end{array}$ \\
\hline Parameter & & \\
At zero time & $\mathrm{a} 8.09^{\mathrm{a}} \pm 1.89$ & $\mathrm{a}^{\mathrm{a}} 7.94^{\mathrm{a}} \pm 0.93$ \\
After 8 weeks & $\mathrm{a}^{\mathrm{a}} 8.4^{\mathrm{a}} \pm 1.45$ & $\mathrm{~b} 7.16^{\mathrm{b}} \pm 1.12$ \\
\hline
\end{tabular}


$\mathrm{Cr}(\mathrm{mg} / \mathrm{dl})$

At zero time

$1.08 \pm 0.13$

$1.06 \pm 0.33$

After 8 weeks

$0.99 \pm 0.11$

$0.97 \pm 0.39$

Estimated GFR

$\left(\mathrm{ml} / \mathrm{min} / 1.73 \mathrm{~m}^{2}\right)$

At zero time

$79.51 \pm 13.1$

$75.13 \pm 21.18$

After 8 weeks

$88.39 \pm 12.24$

$82.03 \pm 25.91$

- Results are considered as Mean $\pm \mathrm{SD}$

- Abbreviations; UA: Uric Acid; Cr: Creatinine; GFR: Glomerular Filtration Rate

- Means in the same row with different superscripts are significantly different at $p<0.05$

- Means in the same column with different subscript are significantly different at $p<0.05$

Table 3: Average changes of uric acid levels (mg/dl) after 8 weeks by gender

\begin{tabular}{|c|c|c|}
\hline Parameter & Gouty Group & Hyperuricemic Group \\
\hline $\begin{array}{l}\text { Average changes in } \\
\text { UA for men }\end{array}$ & $\begin{array}{c}0.26 \pm 0.09 \\
(\mathrm{n}=9)\end{array}$ & $\begin{array}{c}-0.64 \pm 0.32 \\
(\mathrm{n}=7)\end{array}$ \\
\hline $\begin{array}{l}\text { Average changes in } \\
\text { UA for women }\end{array}$ & $\begin{array}{c}0.47 \pm 0.28 \\
(n=6)\end{array}$ & $\begin{array}{c}-0.98 \pm 0.43 \\
(n=8)\end{array}$ \\
\hline $\begin{array}{l}\text { Average changes in } \\
\text { UA for total }\end{array}$ & $\begin{array}{l}0.31 \pm 0.14 \\
\quad(n=15)\end{array}$ & $\begin{array}{c}-0.78 \pm 0.3 \\
(n=15)\end{array}$ \\
\hline
\end{tabular}

- Negative results stand for reduction in uric acid

- Results are considered as Mean $\pm \mathrm{SD}$

- Abbreviation; UA: Uric Acid 


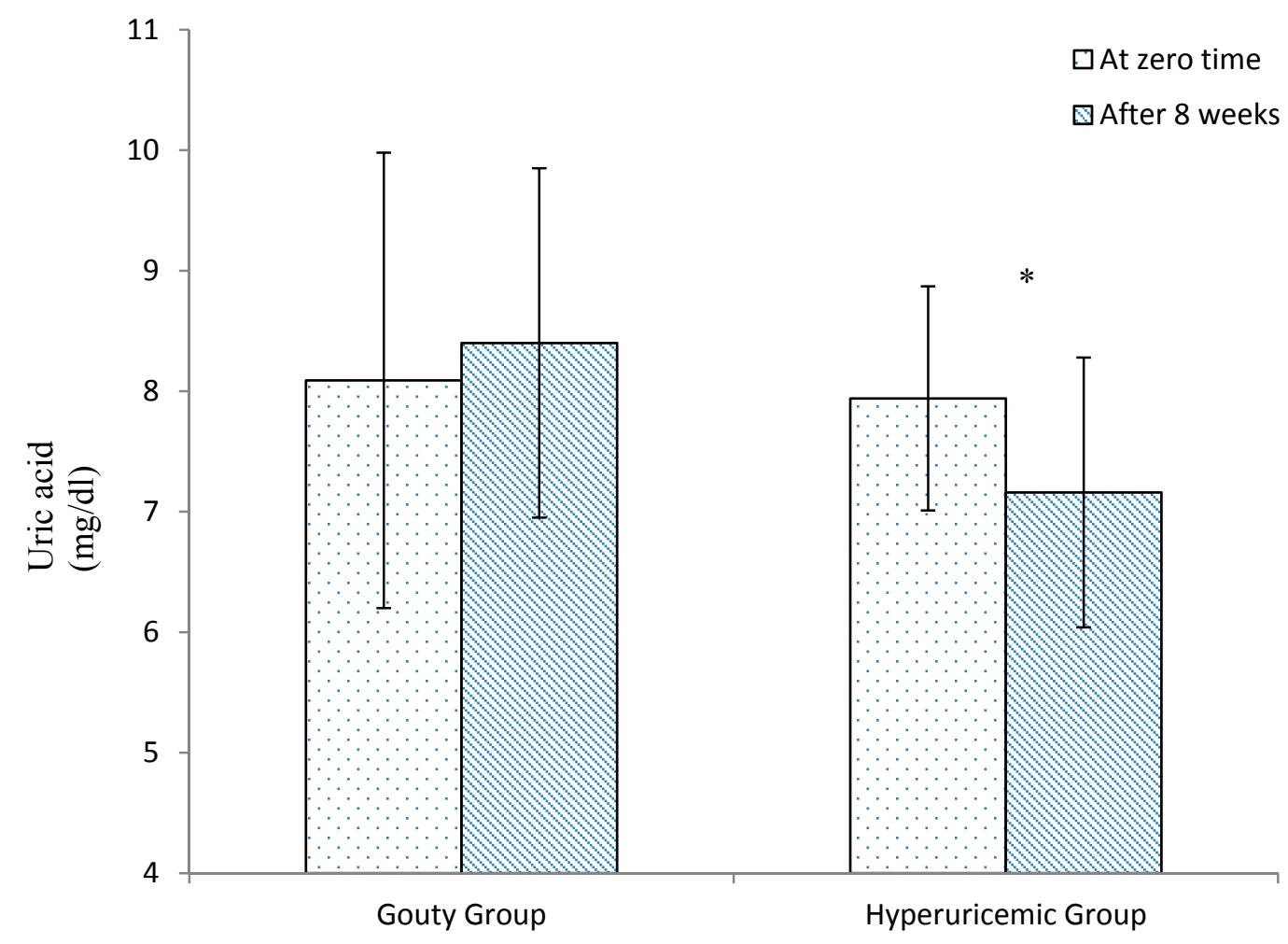

Figure 1: Uric acid changes for gouty and hyperuricemic groups during the study period

* Denotes significant $(p<0.05)$ change

(c) 2016 by the authors; licensee Preprints, Basel, Switzerland. This article is an open access article distributed under the terms and conditions of the Creative Commons by

Attribution (CC-BY) license (http://creativecommons.org/licenses/by/4.0/). 